\title{
Betwixt and Between: Exploring the Liminal Space of the 'First Generation' Filipino Physician Through the Lens of the Rites of Passage
}

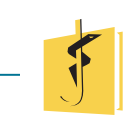

\author{
Lawrence George P. Garcia, $M D^{*}$; \\ Maria Minerva P. Calimag, MD, MSc, PhD*2,3,4; \\ Alejandro C. Baroque II, MD'; \\ Ma. Lourdes P. Corrales-Joson, MD'
}

". . . ordeals, myths, maskings, the presentation of icons to novices, secret languages, food and behavioural taboos create a weird domain in the seclusion camp ... and the novices are induced to think, and think hard, about cultural experiences they had taken for granted."

Victor Turner, From Ritual to Theatre: The Human Seriousness of Play[1]

\section{ABSTRACT}

Introduction: The 'first generation' physician gathers a lot of strength to venture into a world unknown to him. Unlike a physician born to a family of physicians who has a family to guide him, the 'first generation' physician only has himself to survive this endeavor. Through the life worlds of a select group

Lawrence George Garcia

lancegarciamd@gmail.com

Department of Neurology and Psychiatry, UST Hospital

2 Departments of Pharmacology and Clinical Epidemiology, UST Faculty of Medicine and Surgery

3 Research Center for Social Science and Education, University of Santo Tomas

4 Research Center for the Health Sciences, University of Santo Tomas

contributed equally to writing the manuscript of 'first generation' physician-in-training, this study seeks to answer the following central question: How do 'first generation' Filipino physicians collectively characterize their liminal spaces in transition from medical school to clinical practice?

Methodology: Anchored on the Theory of the Rites of Passage, this phenomenological inquiry, intends to surface the lebenswelt or essence of the experience of being the only physician in the family. Respondents comprised a purposive sample of physicians-in-training (residents and fellows), who are the only physicians in the family. Data were gathered using semi-structured interviews. Triangulation and member checking procedures were done to ensure the data reliability. Data were then subjected to cool (categorization) and warm analysis (thematization) using the Colaizzi's method.

Findings and Discussion: With all the transcribed experiences summarized and those with the same meaning analyzed, the following categories and themes were generated: The Intending Facet / Purpose: From Uncertainty towards Redefinition; The Thinking Facet / Process: From Perplexity towards Self-efficacy; The Relating Facet / People: From Isolation towards Integration; and The Transforming Facet / Power: From Vulnerability towards Empowerment. It was shown that a 'first generation' 
physician in this liminal space undergoes challenges and struggles during his training in medicine. This served as his Rite of Passage to transition him to someone dreaming only to become a physician, to become redefined with conviction, supported and integrated into the health system, empowered and transformed to the physician he is meant to be.

Recommendations: Physicians undergo a lot of challenges and mental stress and it means a lot for trainers to enter into the trainees' life-world, especially that of a 'first generation' physician, so that they can build socio-emotional learning and mentoring programs and counselling services that address different facets of liminal space that the trainees go through.

\section{INTRODUCTION}

Being a physician is a very noble profession. Anyone who attempts to study medicine should have a great deal of passion and perseverance to be able to withstand the rigors that it entails. That is why it brings pride to someone who finishes it, especially if that someone is the first in his family. The 'first generation' physician gathered a lot of strength to venture into a world unknown to him. Unlike a physician born to a family of physicians who has a family to guide him, the 'first generation' physician only has himself to survive this endeavor of four years in medical school, one year in internship, three to five years in residency depending on the specialty, and two to three years in fellowship if he still desires. As structured as it may seem, the road to becoming a physician is not always smooth sailing. Certain circumstances can be very litigating and unforgiving.[2] The stress begins as early, but not limited to, during residency. It is known to cause physical and mental stress, which may affect a medical resident's cognitive status, emotional reactivity and way of life. $[3,4]$ The medical journey indeed is a Rite of Passage to the aspiring physician. Over four decades ago, Arnold van Gennep used the term rites of passage to describe the ceremonial and ritualistic behaviors that marked the passage between social roles.

What is fascinating with the 'first generation' physician is that the role as the family's physician gets ascribed to him early on. As early as during medical school or training, all medical attention of the family, as well as other relatives, gets directed to him. All family medical problems become his responsibility.

This places him in a confusing position of not only becoming a trainee, but also the primary physician of the family. Also, taking on the role of the primary physician of the family means dealing with an entire array of medical problems, regardless of the specialization that he/she takes. His dilemma: Should I manage the family's concern first to the best of my knowledge and abilities learned from medical school, or should I immediately refer him to a specialist and risk disappointing my family who entrusted his care to me?

A concept that can explain the journey of an aspiring physician is the concept of liminality. The word liminality, is derived from the Latin word limen, meaning threshold. According to dictionary.com: "liminality is the transitional period or phase of a rite of passage, during which the participant lacks social status or rank, remains anonymous, shows obedience and humility, and follows prescribed forms of conduct, dress, etc.".[5] The idea was introduced to the field of anthropology in 1909 by Arnold Van Gennep in his seminal work, Les Rites de passage. Van Gennep also described rites of passage such as coming-of-age rituals and marriage as having the following three-part structure: separation, liminal period, reassimilation. The initiate (that is, the person undergoing the ritual) is first stripped of the social status that he or she possessed before the ritual, inducted into the liminal period of transition, and finally given his or her new status and reassimilated into society. It was not until the second half of the 20th century, though, that the terms "liminal" and "liminality" gained popularity through the writings of Victor Turner.[1] Turner borrowed and expanded upon Van Gennep's concept of liminality ensuring widespread usage of the concept not only in anthropology, but also in other fields as well. He notes that "the subject of passage ritual is, in the liminal period, structurally, if not physically, 'invisible'." That is, the status of liminal individuals is socially and structurally ambiguous.[6] It has been applied across various disciplines to describe a continuum of human conditions in which the transition occurs from one state to another - usually from lesser mortal to more evolved and mature human, [7] and accompanied 
by an epistemological development of the medical mind in the healthcare profession. [8]

Through the life worlds of a select group of 'first generation' physicians-in-training, this study seeks to answer the following central question: How do 'first generation' Filipino physicians collectively characterize their liminal spaces in transition from medical school to clinical practice?

\section{METHODOLOGY}

This is a qualitative study utilizing the phenomenological approach. Phenomenology aims to study the lived experience of someone. Phenomenology is appropriate in discovering not yet fully explored lived experiences. The approach weaves together a sequence of events through indepth interviews to form a cohesive story and determine certain themes that arise during the observed events, such as the lived experience of 'first generation' physicians.

Respondents included were resident and fellows in training at the University of Santo Tomas Hospital who are the first and only physicians in their family. Based on the objectives of the study and character of the population studies, a combined or mixed purposive sampling was utilized. $[9,10]$

The number of respondents was determined until a saturation point was reached, ie, at a moment during the analysis of the data where the same themes are recurring, and no new insights are given by additional sources of data. Data were gathered from the respondents via an in-depth interview as they narrate their experiences and feelings freely with as little help from the primary investigator as possible. Open-ended questions were employed to encourage the respondents to freely share their experiences. Voice recording was done to capture all the necessary data. The interview had no time limit until all the information was exhausted by the participant. Analysis of information was started when data saturation was reached.

Transcripts of the voice recording provided the main focus of analysis. The transcripts were read and re-read following the steps proposed by Colaizzi to get the feel of sharing. Colaizzi's strategy in descriptive phenomenology will be useful to exhaust all description about the phenomenon being studied.[11] Meanings were extracted and highlighted from the respondents' experiences to get certain themes. These were then summarized to deduce the phenomenology.[12-14] To ensure the truthfulness and trustworthiness of data collected, member checking procedures were done.

\section{FINDINGS}

Semi-structured interviews were conducted with six residents and two fellows who are all trainees at the University of Santo Tomas Hospital. Seven were female, and one was male. Their mean age was 30 years old.

The interviews generated 25 pages and 838 transcription lines of experiences. From these, the researchers read and re-read the transcriptions to get a grasp of the experiences. A total of 222 significant statements were generated. Meanings and statements of the same essence were grouped into categories. These were further refined into theme clusters and emergent themes to get the actual phenomenon of the study.

Upon re-analyzing and redefining the theme clusters, it was observed that a 'first generation' physician undergoes multiple facets of transition during his journey to becoming a specialist, from how he was before towards what he has become now.

The transitioning statements about "What I Was and What I Am" among first generation Filipino physicians through the lens of Rites of Passage centered on the following themes:

\section{The Intending Facet / Purpose: From Uncertainty Towards Redefinition}

The theme is purpose-centered and describes the feeling of discomfort that a 'first generation' physician felt during his journey. It is accompanied by a sense of inadequacy but nevertheless he knows that he has to overcome these as he regains his bearings and-focuses on his dream of being a physician regardless of what it entails.

Being the first physician of the family, he is expected to oblige with such responsibilities that may be overwhelming during the early phases of training. Family and relatives asked questions and he was still unsure about how to answer. He felt distressed.

\footnotetext{
"Relatives would ask me about what medicine or remedy is best for their condition" - AL
} 


\begin{abstract}
"When someone at home is sick, even simply with cough and cold, since I am studying medicine, they ask me for medical advice. Actually, even neighbors ask me [for medical advice]. They're actually expecting a lot from me." - JA
\end{abstract}

He developed a fear of disappointing his family. He got disappointed with himself for mistakes that he committed.

"There was an instance when I was in medical school when it felt like I've let myself down. My cousin went home from the States and eventually developed pneumonia here. I felt disappointed because I was not able to detect it." - AG

At an early stage in his journey, he was burdened already on deciding general health concerns of the family.

"I had an uncle with Stage 4 Lung Cancer. Most of the decision-making were given to me because I was the only one who understood Medicine. I know that the prognosis is poor. When he was brought to the hospital, he needed to be intubated. My relatives let me decide." - JN

He developed dystonic emotions about being a physician to his family.

"I panicked so much when it was my dad. I was still a clerk back then. I felt that my judgments and thinking get clouded whenever immediate family members get sick." - JN

"When confronted with what looks like a stroke. I panicked. I don't know how to respond. All I know is bring someone with a stroke to the hospital." - RO

"When they ask me a question, I have to answer them, to satisfy their concern." $\mathrm{AL}$

As time passed by, despite the discomforts, he realized that he was gradually being redefined to someone capable of treating and helping his family because of the knowledge and skills he acquired through extensive academic and clinical training. He then sensed a change of how his family saw him.
"I am entrusted with the decision-making regarding health concerns because I am the one from the medical field and understands best." - JN

"When they have health concerns, they call me." - JN

"I decided to have my father undergo cardiac bypass surgery." - LL

\section{The Thinking Facet / Process: From Perplexity Towards Conviction}

A 'first generation' physician initially has insecurities. He would hesitate to offer his help because he felt a lack in knowledge to treat a patient, may it be a family member or relative or others. In times that his family asks for help or opinion, he questions his current status: I am still in training, right? Am I a physician already? Why don't I feel like a physician yet? He was perplexed.

"There is still a lot I have to learn."- AL
"All I know are theoretical information."-AG
"If only people know the amount of
knowledge I have now, that it is still not
enough." - JA
"During my first year of moonlighting,
I do not trust myself enough to practice
medicine." - LA
"I would tell them that I have not graduated
yet and that I am still unsure about the
answer to their query."- RO

He felt that he lacks guidance. He compared himself with other physicians born to a family of physicians. "Why am I not as privileged?" he says.

\begin{abstract}
"For those who were born and raised from a family of physicians, someone can guide them. Me, I come from a nonmedical family, I am still learning new things on my own." - AL

"Being the first doctor in my family, I do not have any first-hand experience of what a doctors'personal life is like." - LA
\end{abstract}

Until he continued with his medical journey, from being a student to a resident or fellow-in-training, he noticed that he got exposed to different cases and transitioned to having the confidence to approach and manage patients. 
"You get to know how to work in different situations. I became more confident about managing and treating patients" - AG

"As you progress with training, they also look up to you." - JA

He got exposed to and handled diverse cases until the day came when he became confident about his capabilities, saying to himself that "I can manage. I want to cure this." and decided on the specialty to which he would devote his passion.

"That's the reason whyl took up this specialization." $-\mathrm{JN}$

"I chose this specialization because someone has to take care of our family." - LL

\section{The Relating Facet / People: From Isolation Towards Integration}

As mentioned earlier, part of the struggles of a 'first generation' physician was the dystonic feeling towards the pressure that he experienced. Because of this, he utilized defense mechanisms to overcome anxiety. It was not that he does not want to offer help; he just felt that he was not yet well equipped for the role expected of him initially.

"Whenever I am not sure, I try to mask with
what I know, but if I really do not know
anymore, I just admit to them. It's better than
giving false information anyway." - AL
"I bombard them with questions [during
history taking]. So I can show them that I
am knowledgeable." - JL
"Sometimes I just avoid them. Especially
during reunions, you know that they will
just ask you for something, or consult you.
Sometimes, I hesitate to meet up with
them." - AL
"I don't usually answer phone calls. I feel
agitated whenever someone calls. I opt
not to answer phone calls." - JN

Eventually with constant practice of the art and skill of medicine, he knows what he was capable of and journeys into the open and more integrated self to the community in need of him. The self and responsibility are now syntonic.

"When they have health concerns, they call and reach out to me." - JN

\author{
"They consult me first." - JU \\ "I advised them to come and see me so \\ that I can assess them properly." - JU
}

\section{The Transforming Facet / Power: From Vulnerability} Towards Empowerment

The medical journey comprised of multiple stages that an aspiring physician had to go through. The hierarchy comprises of clerkship, internship, residency and fellowship. Especially during the junior years of the medical journey, the 'first generation' physician feels vulnerable, not only to his colleagues but also to patients in need of his services. His family also do not understand what he is going through and he has no one to run to. The power struggle is inevitable.
"They cannot understand our schedule and the long hours we have to spend in the hospital." - AL
"There are times I don't get to go home on time. They think I am doing something else, that I am not working, or that I am just making an excuse about not going home yet. Those were the days when we had to unexpectedly extend our duty hours." - RO

With much needed rigor, he finally finished his journey. He has reached, or almost if not yet, the pinnacle of medicine. He confidently performed his job and obligations as the physician to his family and community as well. He was now in control. He now had an impact on his environment. He had the power to heal.
"I feel more driven to finish this career that I started. To be able to help others to the best of my abilities." - LY
"They told me that I am more credible than a lay person." - JA
"I try to explain to them so that they can easily understand. I get to help them with decision making." - LL

\section{DISCUSSION}

The journey to become a physician is strenuous. What more for a 'first generation' physician who has no idea of the world that he is about to enter. Being 
the first physician, he also did not have any proper guidance from others. Early on, he felt marginalized when comparing himself to his colleagues who come from a family of physicians. A famous quote attributed to G.S. Becker goes:

Medical schools have been accused, with some justification, I believe, of discrimination against minority groups and favoritism towards relatives of AMA members. Perhaps this explains why doctors' sons more frequently seem to follow in their fathers' footsteps than do sons of other professional men. -G. S. Becker (1959), 217-18 [15]

In 1979, for example, at least $75 \%$ of doctors' sons and daughters were admitted to at least one of the schools of their choice, compared to $66 \%$ of all medical school applicants who were admitted to at least one of the medical schools they applied to.[16]

The 'first generation' physician ventured into this journey with a purpose - to become the physician of his family. He struggled with academic stress initially, second guessed himself and questioned his purpose. [17] When compared with his colleagues belonging to a family of physicians whose purpose in part is to continue their family's legacy, his purpose was different - he wanted to take care of his family, to provide the best health care for them. Until this time arrived, he spent many years of extensive academic and clinical training. During his stay in the liminal space, he gradually grew and blossomed. He redefined himself - towards his true passion, and eventually attained the professional identity [18] for which he had trained over several years. This gave him and his family a great sense of pride. This became a benchmark for his family that he cannot disregard.

Nothing was easy from the start. Rites of Passage in Medicine marks the transition from one status to another - from novice to expert. As a novice he struggled with translating theoretical knowledge into action and found it difficult to talk about expertise. He felt he was lacking, inadequate and incapable. Later on, however, he realizes that educational practices and lots of studying play an important role in enabling or inhibiting the preconditions for expertise in his specialty. As he transitioned to becoming an expert he developed domain-specific "habits of mind" unique to his specialty, so the complexity of routine tasks that challenged him as a novice were soon forgotten. The 'first generation' physician eventually realized that he now shares the status of a co-equal with his colleagues, imbued with shared skills and values, the same habits of inquiry, critical thinking, innovation and improvement along with relevant knowledge and skills after having passed the same ritualized tests, ordeals and challenges. They likewise developed the shared understanding that liminality constitutes processual experiences and becoming an expert is a socially embedded process.

He stayed in this liminal space until he was proven worthy of the title of a specialist. Little did he know that this was his rite of passage to becoming a fullfledged specialist. As a novice, he assumed that written procedures were specific enough to address every clinical contingency whereas expertise clothed him with the confidence to know that rules and standards were essentially underspecified. As a novice in his liminal state, he needed to familiarize himself less with written standards than to learn the unwritten, quasi-normative rules of his supervising consultant. Moreover, as a novice he conceptualized decision-making as a rational, linear process. As he transitioned to becoming an expert, however, he realized the importance of tacit knowledge and intuitive decision-making. [19]

As a medical student, he remembered that he was fascinated at how his supervising consultant managed to comfort his patients who were critically ill and how he yearned to also master that skill. He knew that eventually he will be able to attain the precision, as well as the perfection coming from years of experience. He began to realize that being a physician is not a child's play and even decades of training may not be sufficient.[20] Over time he integrated himself into this world that was once foreign to him.

At first, he felt vulnerable from his lack of power over this world that he was unfamiliar to. He realized that there are power relations and a culture that promotes hierarchy during specialist training. [21] Gradually, he started to speak up for the sake of the patient.[22] He became certain, no longer confused, that this was what he really wanted to do and the life journey that he wanted to pursue.

For him, the journey was immensely psychological and emotionally stressful and not simply one of physical struggle or pain. The pain of the ordeal was also accompanied by the sense of alienation or distance he had to endure away from his family and community through long hours of ward duty spent with critically-ill patients, delayed and prolonged 
surgical hours, missed family reunions and holidays spent away from home. For the 'first generation' physician, success came with overcoming liminality, managing his stressors and enduring the initiation of being a 'stranger' in the medical field. Finally, he was empowered through his community of fellow physicians and was able to share his power with others as well.

\section{CONCLUSION}

As enticing it is to feel the pride associated with becoming a physician, the journey to withstand it is also harrowing. A great deal of perseverance, commitment and passion is required. Double, if possible, for 'first generation' physicians because they have no one to relate to in the unknown world he was undertaking. In his journey, he underwent many struggles and challenges, ups and downs, to transition himself from where he was before to where he is now and where he will supposedly be in the future.

\section{Implications of the Study}

This study shows the "Rite of Passage" of a 'first generation' physician to become a physician. They undergo a lot of pressure and stress, especially having no one to relate to them. This study helped us better understand the emotional struggles of physicians in training.
As a trainee, physicians undergo a lot of challenges and mental stress and it means a lot for a trainer to enter into the trainees' life-world, especially that of a 'first generation' physician, so they can build mentoring and counseling services that address the different facets of liminal space their trainees go through. Indeed, there is a need to gain an understanding of the ethical and value-laden issues affecting trainees as they begin their clinical work; one needs to hear their personal stories, honestly describing the many formative experiences encountered and told from the heart.

The first physicians in the family will not only benefit from the mentoring and counseling services, but also any medical personnel as well. Proper briefing for both trainees and relatives will make them aware of what to expect during training. Through this, the trainee can also better prepare for the future.

\section{Conflict of Interest}

The investigators have nothing to disclose. No conflicts of interest or biases were identified. The primary investigator only served as a researcher and not as a healthcare provider.

\section{Conduct of the Study}

Protocol was submitted and approved with number IRB-201808-166-TR. There are no biological specimens handled in this research. The data used in the study were gathered through indepth interviews with the respondents. 


\section{REFERENCES}

1. St John, G. Victor Turner and contemporary cultural performance: An introduction. Victor Turner and contemporary cultural performance, 2008; 1-37.

2. Kumar S. Burnout and doctors: prevalence, prevention and intervention. Healthcare [Internet]. 2016 Jun 30;4(3):37. Available from: http://dx.doi.org/10.3390/ healthcare4030037

3. Abdulghani $H$, Alharbi $M$, Irshad $M$. Stress and its association with working efficiency of junior doctors during three postgraduate residency training programs. NDT [Internet]. 2015 Dec;3023-9. Available from: http:// dx.doi.org/10.2147/NDT.S92408

4. Abdulghani $H$, Irshad $M, A$ A Zunitan $M$, Al Sulihem $A, A l$ Dehaim M, Al Esiafir W, et al. Prevalence of stress in junior doctors during their internship training: a cross-sectional study of three Saudi medical colleges' hospitals. NDT [Internet]. 2014 Sep; 1879. Available from: http://dx.doi. org/10.2147/NDT.S68039

5. Grad LB. Liminality: The threshold betwixt and between [Internet]. HuffPost; 2016. Available from: https://www. huffpost.com/entry/liminality-the-threshold-_b_13845666

6. Shure CL. What is liminality? [Internet]. Liminality. The space in between. 2005 [cited 2020]. Available from: http://www.liminality.org/about/whatisliminality

7. Dauphin S, Van Wolputte S, Jansen L, De Burghgraeve $T$, Buntinx $F$, van den Akker M. Using liminality and subjunctivity to better understand how patients with cancer experience uncertainty throughout their illness trajectory. Qualitative Health Research. 2020 Feb;30(3):356-65.

8. Calimag M. The epistemological development of the medical mind among anesthesiologists: Polarity, plurality and perfectivity. Philipp J Anesthesiol. 2013;24(1):26-32.

9. Crossman A. Understanding purposive sampling [Internet]. Thoughtco.com. [cited 2020]. Available from: https:// www.thoughtco.com/purposive-sampling-3026727

10. Nastasi B. Qualitative research: sampling and sample size considerations [Internet]. Available from: https:// my.laureate.net/Faculty/docs/Faculty\%20Documents/ qualit res smpl size consid doc

11. Abu Shosha G. Employment of Colaizzi's strategy in descriptive phenomenology: a reflection of a researcher. European Scientific Journal. 2012 Jan;

12. Janet W. (2017) Phenomenologic Research Guidelines [Internet]. Available from: https://www.capilanou.ca/ psychology/student-resources/research-guidelines/ Phenomenological-Research-Guidelines/

13. Stan L. An Introduction to Phenomenological Research [Internet]. Available from: https://www. rgs.org/NR/rdonlyres/F50603E0-4 1 AF-4B 1 5-9C84BA7E4DE8CB4F/0/Seaweedphenomenologyresearch.pdf

14. Grand Canyon University. Phenomenology methods and data collection [Internet]. Center for Innovation in Research and Teaching. 2019 [cited 2020]. Available from: https:// cirt.gcu.edu/research/developmentresources/research_ ready/phenomenolog y/methods_data

15. Becker GS. (2010). The economics of discrimination. University of Chicago press.

16. Lentz BF Laband DN (1989). Why so many children of doctors become doctors: Nepotism vs. human capital transfers. Journal of Human Resources, 396-413.

17. Garan-Giller EA, Dator DCS, Juan MBA, Querubin GAR, Sevilla TP, Calimag MMP. Life in a tightrope: an interpretive phenomenological analysis of narratives of coping with academic stress among Filipino medical students. Journal of Medicine University of Santo Tomas 2019 DOI: 10.35460/2546-1621.2019-0001 [Internet]. Available from: https://www.researchgate.net/ publication/333570257_Life_on_a_Tightrope_An_ Interpretive_Phenomenological_Analysis_of_Narratives_of Coping_with_Academic_Stress_among_Filipino_Medical_ Students

18. Cruess RL, Cruess SR, Steinert Y. Amending Miller's pyramid to include professional identity formation. Academic Medicine. 2016 Feb 1;91 (2):180-85.

19. Ten Cate O, Carraccio C, Damodaran A, Gofton W, Hamstra SJ, Hart DE, et al. Entrustment decision making: extending Miller's pyramid. Academic Medicine. 2021 Feb $1 ; 96(2): 199-204$.

20. Puri O. The doctor I want to be. Journal of Medical Evidence. 2020 Jan 1;1(1):65-.[Internet]. Available from: https://www.researchgate.net/profile/Oshin-Puri/ publication/343336673_The_Doctor_'I'_want_to_be/ links/5f2408eb92851 cd302 cb4edb/The-Doctor-l-wantto-be.pdf

21. Crowe S, Clarke N, Brugha R. 'You do not cross them': Hierarchy and emotion in doctors' narratives of power relations in specialist training. Social Science \& Medicine. 2017 Aug 1;186:70-77.

22. Hurley J, Hutchinson M. Hierarchy and medical error: Speaking up when witnessing an error. Safety Science. 2020 May $1 ; 125: 104648$.

(c) (i) Open Access This article is licensed under a Creative Commons Attribution 4.0 International License, which permits use, sharing, adaptation, distribution and reproduction in any medium or format, as long as you give appropriate credit to the original author(s) and the source, provide a link to the Creative Commons license, and indicate if changes were made. The images or other third party material in this article are included in the article's Creative Commons license, unless indicated otherwise in a credit line to the material. If material is not included in the article's Creative Commons license and your intended use is not permitted by statutory regulation or exceeds the permitted use, you will need to obtain permission directly from the copyright holder. To view a copy of this license, visit http://creativecommons.org/licenses/by/4.0/. 